\title{
Mitochondria directly influence fertilisation outcome in the pig
}

\author{
Shahinaz H El Shourbagy, Emma C Spikings, Mariana Freitas and Justin C St John \\ The Mitochondrial and Reproductive Genetics Group, The Medical School, The University of Birmingham, \\ Birmingham B15 2TT, UK
}

Correspondence should be addressed to J C St John; Email: j.stjohn.1@bham.ac.uk

S H El Shourbagy and E C Spikings contributed equally to this study

\begin{abstract}
The mitochondrion is explicitly involved in cytoplasmic regulation and is the cell's major generator of ATP. Our aim was to determine whether mitochondria alone could influence fertilisation outcome. In vitro, oocyte competence can be assessed through the presence of glucose-6-phosphate dehydrogenase (G6PD) as indicated by the dye, brilliant cresyl blue (BCB). Using porcine in vitro fertilisation (IVF), we have assessed oocyte maturation, cytoplasmic volume, fertilisation outcome, mitochondrial number as determined by mtDNA copy number, and whether mitochondria are uniformly distributed between blastomeres of each embryo. After staining with $B C B$, we observed a significant difference in cytoplasmic volume between $B C B$ positive $\left(\mathrm{BCB}^{+}\right)$and $\mathrm{BCB}$ negative $\left(\mathrm{BCB}^{-}\right)$oocytes. There was also a significant difference in mtDNA copy number between fertilised and unfertilised oocytes and unequal mitochondrial segregation between blastomeres during early cleavage stages. Furthermore, we have supplemented $\mathrm{BCB}^{-}$oocytes with mitochondria from maternal relatives and observed a significant difference in fertilisation outcomes following both IVF and intracytoplasmic sperm injection (ICSI) between supplemented, sham-injected and non-treated $\mathrm{BCB}^{-}$oocytes. We have therefore demonstrated a relationship between oocyte maturity, cytoplasmic volume, and fertilisation outcome and mitochondrial content. These data suggest that mitochondrial number is important for fertilisation outcome and embryonic development. Furthermore, a mitochondrial pre-fertilisation threshold may ensure that, as mitochondria are diluted out during post-fertilisation cleavage, there are sufficient copies of mtDNA per blastomere to allow transmission of mtDNA to each cell of the post-implantation embryo after the initiation of mtDNA replication during the early postimplantation stages.

Reproduction (2006) 131 233-245
\end{abstract}

\section{Introduction}

Through its various biochemical pathways, the mitochondrion generates ATP, which is necessary for cellular homeostasis and function (Moyes et al. 1998). The inner membrane of the mitochondrion houses the mitochondrial genome (mtDNA). In the pig, this extranuclear genome is approximately $16.7 \mathrm{~kb}$ in size (Ursing \& Arnason 1998). mtDNA encodes 13 of the subunits of the electron transfer chain (ETC) complexes, associated with the process of oxidative phosphorylation (OXPHOS), along with 22 tRNAs and 2 rRNAs that are necessary for mRNA expression (Anderson et al. 1981). Expression of these mitochondrial genes is vital for cellular function, especially as the ETC is the cell's major generator of ATP (Moyes et al. 1998) whilst mutation or deletion can result in severe cellular impairment (Wallace 1999).

Although little is known about porcine oocyte mtDNA copy number, there is considerable intra-ovarian variability in copy number amongst other species. Mature murine oocytes contain mean mtDNA copy number values between 119000 (Piko \& Taylor 1987) and 159000 (Steuerwald et al. 2000), whilst bovine oocytes possess a mean of 260000 copies (Michaels et al. 1982). However, in the human, the variability ranges between 20000 and 598000 copies, with a mean of 193000 (Reynier et al. 2001). Other reports in the human suggest mean values of 256000 (May-Panloup et al. 2005), 314000 (Steuerwald et al. 2000) and 795000 (Barritt et al. 2002) copies. This variability in the human most likely reflects the vast range of patients analysed. For example, those oocytes failing to fertilise due to poor sperm quality and deemed to be indicative of good oocyte quality had a significantly higher mtDNA copy number than poor quality oocytes which were fertilised by good quality sperm (mean 255000 versus 152000 copies; Reynier et al. 2001). Furthermore, poor quality oocytes obtained from 
patients with ovarian insufficiency contained an average of only $100000 \mathrm{mtDNA}$ copies compared with an average of 256000 copies in control oocytes (May-Panloup et al. 2005). In all, this high variability in mtDNA copy and the association with various forms of infertility could reflect a critical threshold of mtDNA copy number that is required for fertilisation to ensue and for subsequent embryonic development. In the mouse, this threshold level has been predicted to be approximately 100000 copies per oocyte (Piko \& Taylor 1987).

In the mouse, mtDNA replication is thought to be absent during preimplantation embryo development (Piko \& Taylor 1987). Consequently, all mitochondrially derived ATP-requiring activities of the early embryo, up to compaction, will be dependent on a predetermined number of mitochondria present in the oocyte at metaphase II (MII). At compaction, there tends to be a switch in various mammalian species, including the pig (Machaty et al. 2001), from OXPHOS to glycolysis (discussed in Van Blerkom et al. 2000). Interestingly, during pig oocyte maturation, mitochondria move from a peripheral location and disperse around the oocyte (Cran 1985, Sun et al. 2001) whilst also becoming more heterogeneous and granulated (Torner et al. 2004). After fertilisation, changes in mitochondrial distribution continue as they cluster around the nuclei during cell division in the early cleavage stages (Sun et al. 2001). It is, however, evident from parthenogenetically activated pig oocytes that the lack of microtubule networks restricts these mitochondrial dynamics (Brevini et al. 2005).

The importance of ATP levels during in vitro maturation has been demonstrated in bovine oocytes. Higher quality oocytes, assessed by morphology, contained significantly higher ATP levels and produced significantly higher blastocyst rates after fertilisation (Stojkovic et al. 2001). In this respect, human oocytes require at least 2 pmol ATP at fertilisation to enhance development and implantation (Van Blerkom et al. 1995). Furthermore, a correlation between mitochondrial distribution in individual blastomeres and blastomere ATP content suggests that the ATP contained within early embryos is likely to be mitochondrially derived (Van Blerkom et al. 2000). To this extent, we have previously hypothesised that oocytes without sufficient mtDNA, and therefore the capacity to generate ATP, would not normally be ovulated. In the case of in vitro fertilisation (IVF), such oocytes result from superovulation protocols (St John 2002a). This could also apply to those oocytes harvested for in vitro embryo production.

Increases in production and storage of energy substrates are another key element of oocyte maturation and many of these production processes require the reducing power of NADPH (Marchal et al. 2001). NADPH is produced via the pentose phosphate pathway, of which the rate-limiting enzyme is glucose-6-phosphate dehydrogenase (G6PD). G6PD is synthesised and accumulates during the oocyte growth phase. Its activity is decreased once this phase has been completed and oocytes are then likely to have achieved developmental competence (Tian et al. 1998).

Brilliant cresyl blue (BCB) is a dye that can be broken down by G6PD (Tian et al. 1998). Oocytes undergoing growth and those that have completed their growth phase will therefore have differing levels of G6PD. Oocytes not containing sufficient G6PD to reduce the dye, stain blue and are more likely to have completed their growth phase and be developmentally competent. Those occytes not staining blue contain G6PD and reduce the dye to a colourless solution. These oocytes are likely to be still growing and not developmentally competent. Furthermore, blue, $\mathrm{BCB}$ positive $\left(\mathrm{BCB}^{+}\right)$pig oocytes show higher sperm penetrability than $\mathrm{BCB}$ negative oocytes $\left(\mathrm{BCB}^{-}\right.$; Roca et al. 1998) and for goat oocytes, higher fertilisation rates have been recorded (Rodriguez-Gonzalez et al. 2002).

Cytoplasmic volume is also an important indicator of oocyte competence. In mice, it has been demonstrated that up to $50 \%$ of the oocyte cytoplasm can be lost with minimal effects on fertilisation and development. However, any further cytoplasmic loss, although resulting in fertilisation, prevents development to the 2-cell stage (Wakayama \& Yanagimachi 1998). Similarly, removal of between 12 and 52\% mouse oocyte cytoplasm resulted in some development to term, although fusion of two resulting 2-cell embryos increased the proportion of live offspring 4- to 10-fold (Zernicka-Goetz 1998). As the cleavage of early embryos does not include a growth phase, it would be likely that human oocytes with very low cytoplasmic volumes would simply not have enough cytoplasmic content to produce the number of divisions and dilutions required to sustain development (Van Blerkom et al. 1998, St John 2002b).

Cytoplasmic transfer (CT), the supplementation of an oocyte with donor cytoplasm, has been proposed as a mechanism for rescuing those oocytes from women with repeated developmental failure (Cohen et al. 1997, 1998). This is particularly the case for older women with poor quality oocytes (Barritt et al. 2001a), who following CT then progress to achieve on-going pregnancies and offspring (Barritt et al. 2001a). However, the contents of the transferred cytoplasm are likely to be mixed possibly containing mRNAs, mitochondria and mtDNA. Consequently, it is not clear whether this developmental arrest arises from insufficient cytoplasmic factors or insufficient numbers of mitochondria to support metabolic function.

Studies in the mouse and the human have indicated an important role for mtDNA copy number in fertilisation, whilst cytoplasmic supplementation has demonstrated an influence on embryonic development. However, there is little data related to mtDNA content in the pig oocyte and embryo. Furthermore, the importance of mitochondrial number to porcine fertilisation outcome and embryonic development needs to be clearly determined. Here, we have (1) used BCB to determine the relationship between mtDNA copy number and oocyte volume, growth and development, (2) analysed the distribution of 
mitochondria in individual blastomeres post-fertilisation to determine whether cellular division regulates mitochondrial division, and (3) supplemented incompetent oocytes with pure populations of mitochondria from competent oocytes to determine whether supplementary mitochondria can influence fertilisation outcome. Our results demonstrate that mtDNA copy number in mature pig oocytes has a strong influence on fertilisation outcome.

\section{Materials and Methods}

All chemicals and reagents were purchased from Sigma Chemical Co. (Poole, Dorset, UK) unless otherwise stated. All statistical tests were performed using Minitab Statistical Software 13.1 (Minitab Inc., State College, PA, USA). All statistical comparisons performed were considered statistically significant at $P<0.05$.

\section{Oocyte retrieval}

Ovaries were collected from a slaughterhouse in $0.9 \%$ saline $(\mathrm{w} / \mathrm{v})$ supplemented with $75 \mu \mathrm{g} / \mathrm{ml}$ potassium penicillin $\mathrm{G}$ and $50 \mu \mathrm{g} / \mathrm{ml}$ streptomycin sulphate at $25-30^{\circ} \mathrm{C}$. They were rinsed three times with PBS at $39^{\circ} \mathrm{C}$ and transferred to a laminar flow hood for cumulus oocyte complex (COC) aspiration from follicles with a diameter of $3-6 \mathrm{~mm}$.

\section{In vitro maturation of oocytes}

Oocytes were matured in $100 \mu \mathrm{l}$ in vitro maturation $(\mathrm{IVM})_{1}$. This consisted of NCSU-23 (Petters \& Wells 1993; see Table 1), supplemented with $10 \%(\mathrm{v} / \mathrm{v})$ porcine

Table 1 Composition of base media used during the IVF protocol.

\begin{tabular}{|c|c|c|c|}
\hline \multirow[b]{2}{*}{ Ingredient } & \multicolumn{3}{|c|}{$\begin{array}{l}\text { Concentration ( } \mathrm{mM} \text {, unless otherwise } \\
\text { specified) }\end{array}$} \\
\hline & NCSU-23 & IVF media & TL-Hepes \\
\hline $\mathrm{NaCl}$ & 108.73 & 113.1 & 113.7 \\
\hline $\mathrm{KCl}$ & 4.78 & 3 & 3.22 \\
\hline $\mathrm{KH}_{2} \mathrm{PO}_{4}$ & 1.19 & 0 & 0 \\
\hline $\mathrm{MgSO}_{4} \cdot 7 \mathrm{H}_{2} \mathrm{O}$ & 1.19 & 0 & 0 \\
\hline $\mathrm{NaHCO}_{3}$ & 25.07 & 0 & 2 \\
\hline Glutamine & 1 & 0 & 0 \\
\hline Glucose & 5.55 & 11 & 0 \\
\hline Taurine & 7 & 0 & 0 \\
\hline Hypotaurine & 5 & 0 & 0 \\
\hline $\mathrm{CaCl}_{2} \cdot 2 \mathrm{H}_{2} \mathrm{O}$ & 1.7 & 7.5 & 2.04 \\
\hline BSA (mg/ml) & 0 & 4 & 0 \\
\hline Tris & 0 & 20 & 0 \\
\hline Pyruvate & 0 & 5 & 0.2 \\
\hline Na lactate & 0 & 0 & 12.95 \\
\hline $\mathrm{NaH}_{2} \mathrm{PO}_{4}$ & 0 & 0 & 0.34 \\
\hline Phenol red & 0 & 0 & 0.027 \\
\hline $\mathrm{MgCl}_{2} 6 \mathrm{H}_{2} \mathrm{O}$ & 0 & 0 & 0.50 \\
\hline FCS $(\mu \mathrm{l} / \mathrm{ml})$ & 0 & 0 & 10 \\
\hline Penicillin-G & 0 & 0 & 1.08 \\
\hline Gentamycin ( $\mu \mathrm{g} / \mathrm{ml})$ & 0 & 0 & 25 \\
\hline Hepes & 0 & 0 & 10 \\
\hline
\end{tabular}

www.reproduction-online.org follicular fluid, and $20 \mathrm{U} / \mathrm{ml}$ human chorionic gonadotrophin (Profasi 5000, Sigma), $0.1 \mu \mathrm{g} / \mathrm{ml}$ epidermal growth factor (EGF) and $0.1 \mathrm{mg} / \mathrm{ml}$ cysteine overlaid with equilibrated mineral oil and incubated at $39^{\circ} \mathrm{C}, 5 \% \mathrm{CO}_{2}$ in air for 20-22 h. After $22 \mathrm{~h}$, the oocytes were washed three times in $\mathrm{IVM}_{2}$ (NCSU-23 supplemented with $0.1 \mu \mathrm{g} / \mathrm{ml}$ EGF) before being placed in $100 \mu \mathrm{l}$ droplets of IVM $\mathrm{IVver-}_{2}$ laid with equilibrated mineral oil, and incubated at $39^{\circ} \mathrm{C}$, $5 \% \mathrm{CO}_{2}$ in air for a further $20-22 \mathrm{~h}$.

\section{Brilliant cresyl blue (BCB) test}

Oocytes were washed 3 times in modified Dulbecco PBS (DPBSm, Dulbecco PBS supplemented with $0.4 \%(\mathrm{w} / \mathrm{v})$ BSA (fraction V), $0.34 \mathrm{mM}$ pyruvate, $5.5 \mathrm{mM}$ glucose and $50 \mu \mathrm{g} / \mathrm{ml}$ gentamycin). Oocytes were exposed to $13 \mu \mathrm{M}$ $\mathrm{BCB}$ diluted in DPBSm, and then incubated at $39^{\circ} \mathrm{C}, 5 \%$ $\mathrm{CO}_{2}$ in air for $90 \mathrm{~min}$. The control oocyte group was incubated in DPBSm without BCB for $90 \mathrm{~min}$. After incubation, the oocytes were transferred to DPBSm and washed three times. During the washing procedure, the oocytes were examined under a stereomicroscope and classified according to: (i) blue cytoplasmic staining $\left(\mathrm{BCB}^{+}\right.$group), (ii) a colourless cytoplasm ( $\mathrm{BCB}^{-}$group), and a non-BCB-treated group (control).

\section{Sperm preparation}

Sperm were obtained from pure bred boars supplied by JSR Genetics (Driffield, East Yorkshire, UK). The heavy particles were removed by centrifugation of the whole semen sample at 50 r.p.m. for $3 \mathrm{~min}$. The supernatant was then centrifuged at 1200 r.p.m. for $5 \mathrm{~min}$ and the pellet resuspended in $3 \mathrm{ml}$ sperm preparation media (DPBS supplemented with $1 \mathrm{mg} / \mathrm{ml}$ BSA, $100 \mu \mathrm{g} / \mathrm{ml}$ potassium penicillin $\mathrm{G}$ and $75 \mu \mathrm{g} / \mathrm{ml}$ streptomycin) followed by centrifugation at 1200 r.p.m. for $5 \mathrm{~min}$. The pellet was resuspended in $3 \mathrm{ml}$ sperm preparation media and layered onto a 95\%:45\% Percoll gradient before centrifugation at 1500 r.p.m. for $25 \mathrm{~min}$. The $90 \%$ fraction was resuspended in $2 \mathrm{ml}$ IVF media (Koo et al. 2000; see Table 1). The supernatant was finally centrifuged at 1500 r.p.m. for $5 \mathrm{~min}$ and the pellet resuspended in $1 \mathrm{ml}$ IVF media. Sperm counts were performed and samples were diluted to give a final concentration of $1 \times 10^{6} / \mathrm{ml}$.

\section{In vitro fertilisation}

Following IVM, oocytes were washed three times in IVF media and were repeatedly drawn through a fine pipette to strip the cumulus cells; they were then placed in $100 \mu \mathrm{l}$ drops of IVF media overlaid with equilibrated mineral oil. Diluted sperm $(50 \mu \mathrm{l})$ were added to $100 \mu \mathrm{l}$ of the IVF media containing the mature oocytes and these were incubated at $39^{\circ} \mathrm{C}, 5 \% \mathrm{CO}_{2}$ in air for $15-18 \mathrm{~h}$. 


\section{Embryo maturation}

After sperm-oocyte co-incubation, putative zygotes were washed three times in IVP medium (NCSU-23 supplemented with 0.4\% BSA; Abeydeera \& Day 1997) and cultured in $100 \mu \mathrm{l}$ of the same media overlaid with equilibrated mineral oil and incubated at $39{ }^{\circ} \mathrm{C}, 5 \% \mathrm{CO}_{2}$ in air. Cleavage and blastocyst formation were evaluated under a stereomicroscope, at 48 and $144 \mathrm{~h}$ after insemination respectively.

\section{Measurement of oocyte diameter}

Individual oocyte diameters (D) were measured immediately after BCB incubation. Ten oocytes from each culture dish were individually pipetted into $5 \mu$ d droplets of IVM $_{1}$ media, and examined at $\times 200$ magnification on an inverted microscope at $39^{\circ} \mathrm{C}$. Oocyte volume (V) was then calculated using the standard formula: $V=4 / 3 \pi(D / 2)^{3}$. The volumes of $\mathrm{BCB}^{+}, \mathrm{BCB}^{-}$and control oocytes were analysed by one-way ANOVA and Tukey's pairwise comparisons.

\section{Preparation of oocytes and blastomeres for mtDNA analysis}

Both zona pellucida (ZP) and attached sperm were removed by exposing each fertilised or unfertilised oocyte to $10 \mathrm{U} / \mathrm{ml}$ pronase in IVP media for 1-1.5 min (Fong et al. 2001). ZP-free unfertilised oocytes and intact embryos were washed several times in IVP media and transferred to $0.2 \mathrm{ml}$ PCR tubes (Appleton Wood Laboratory Equipment, Birmingham, UK). Individual blastomeres were disassociated by exposing the intact denuded embryos to $10 \mathrm{U} / \mathrm{ml}$ pronase in IVP media for $1 \mathrm{~min}$ followed by repeated pipetting in IVP media. Each blastomere was transferred to a separate $0.2 \mathrm{ml} \mathrm{PCR}$ tube.

\section{DNA extraction}

Autoclaved sterile double distilled $\mathrm{H}_{2} \mathrm{O}\left(\mathrm{dd} \mathrm{H}_{2} \mathrm{O} ; 20 \mu \mathrm{l}\right)$ was added to each individual frozen oocyte, zygote or embryo and $10 \mu \mathrm{l}$ were added to each blastomere. The samples were then subjected to freeze-thaw disruption as previously described (Findlay et al. 1996). Total DNA was isolated from blood samples from 37 sows representative of the whole dam line. DNA was extracted according to the whole blood DNA isolation protocol using the Puregene DNA Isolation Kit (Flowgen, Nottingham, UK).

\section{Generation of DNA standards for real time PCR}

The external standard of $369 \mathrm{bp}$ was generated as previously described (Reynier et al. 2001) using primers designed to amplify the cytochrome B gene (see Table 2). Reactions were performed in $50 \mu \mathrm{l}$ using $1 \times$ PCR buffer (Bioline, London, UK), $1.5 \mathrm{mM} \mathrm{MgCl} 2$ (Bioline), $0.5 \mu \mathrm{M}$ each primer, $200 \mu \mathrm{M}$ dNTP mix (Bioline) and $2 \mathrm{U}$ BioTaq polymerase (Bioline). It was assumed that $1 \mathrm{ng}$ of the $369 \mathrm{bp}$ PCR product contains $2.47 \times 10^{9}$ molecules of double stranded DNA. These samples were then serially diluted 10 -fold in order to construct a standard curve for PCR quantification.

\section{Real time PCR quantification}

Real time PCR was performed on an iCycler iQ Real Time Detection System (BIO-RAD, USA) in $20 \mu \mathrm{l}$ reactions using a 96-well PCR plate (Abgenix, Epson, UK) containing $1 \times$ buffer (Bioline), $0.2 \mathrm{mM}$ dNTP Master Mix (Bioline), $4 \mathrm{mM} \mathrm{MgCl}_{2}$ (Bioline), $0.5 \mu \mathrm{M}$ each primer, $0.25 \mathrm{U}$ Sybr Green, $2 \cup$ BioTaq DNA polymerase (Bioline) and $2 \mu \mathrm{l}$ of each oocyte or blastomere sample. The reaction conditions were 1 cycle at $95^{\circ} \mathrm{C}$ for 3 min followed by 50 cycles of $94^{\circ} \mathrm{C}$ for $30 \mathrm{~s}, 55^{\circ} \mathrm{C}$ for $30 \mathrm{~s}$ and $72{ }^{\circ} \mathrm{C}$ for $30 \mathrm{~s}$. iCycler software generated a standard curve. This then allowed the determination of the starting copy number of mtDNA in each sample. A melting curve was analysed in order to check for the absence of mispriming and the quality of amplifications. All samples were tested twice and the mean starting quantity of mtDNA was calculated by the iCycler software.

The difference in mtDNA copy number between fertilised and unfertilised oocytes in each group was analysed by unpaired Student's $t$-test. The data from the three BCB groups were analysed by one-way ANOVA and Tukey's pairwise comparisons and the distribution of mtDNA copy number in different blastomeres of each embryo was analysed by one-way ANOVA and Multi-Vari chart. The Student's $t$-test and the one-way ANOVA for mtDNA copy number were performed after logarithmic transformation of the data.

\section{Fractionation of mitochondria}

The ZP of $\mathrm{BCB}^{+}$oocytes were removed as described above, and then washed in $\mathrm{IVM}_{2}$ medium. The ZP-free oocytes were cultured in $\mathrm{IVM}_{2}$ supplemented with $0.5 \mu \mathrm{g} / \mathrm{ml}$ MitoTracker Green, a mitochondrial-specific

Table 2 Primer sequences for PCR and real time PCR.

\begin{tabular}{|c|c|c|c|c|}
\hline Product & Forward primer & Reverse primer & Annealing temp & Product size $(b p)$ \\
\hline Cytochrome B & GGA ATC TCA TCA GAC ATA GAC & GAG GTC TGC TAC TAG TAT TC & 55 & 368 \\
\hline$\beta$-Actin & CCA TGT ACG TGG CCA TCC AGG CTG & GGA GAT GGC CAC CGC GGC CTC & 67 & 259 \\
\hline Cyclin B DNA & GTC GTG AAG TCA CTG GAA AC & CCA TCT GCC TGA TTT GGT AC & 55 & 470 \\
\hline Cyclin B cDNA & GTC GTG AAG TCA CTG GAA AC & CCA TCT GCC TGA TTT GGT AC & 55 & 236 \\
\hline D-loop & GCA TTC CAT TCG TAT GCA AAC C & TCA TGA TCC GGC CGA CAA T & 67 & 606 \\
\hline
\end{tabular}


fluorescent probe, for $30 \mathrm{~min}$. After preloading of the fluorescent probe, ZP-free oocytes were cultured in $100 \mu \mathrm{l}$ $\mathrm{IVM}_{2}$ supplemented with $1 \mu \mathrm{g} / \mathrm{ml}$ cytochalasin D (CCD) for $1 \mathrm{~h}$ at $39^{\circ} \mathrm{C}$ in $5 \% \mathrm{CO}_{2}$ in air. The ZP-free $\mathrm{BCB}^{+}$ oocytes were centrifuged in $100 \mu \mathrm{I} \mathrm{IVM}_{2}$ at $1500 \mathrm{~g}$ for $10 \mathrm{~min}$ to pellet the nuclei and unbroken cells. The supernatant was centrifuged at $9500 \mathrm{~g}$ for another $10 \mathrm{~min}$ to concentrate the cytoplasts. These were then transferred in $0.5 \mathrm{ml} \mathrm{IVM}$ medium containing $1 \mu \mathrm{g} / \mathrm{ml} \mathrm{CCD}$ to the surface of $48 \%$ Percoll solution and centrifuged at $19600 \mathrm{~g}$ for $2 \mathrm{~h}$. The cytoplasts were recovered from the lower portions of the centrifuge tube and transferred to a $20 \mu \mathrm{l}$ droplet of TL-Hepes medium (see Table 1).

\section{Mitochondrial supplementation}

Recipient $\mathrm{BCB}^{-}$oocytes that had matured in vitro for $24 \mathrm{~h}$ were incubated at $39^{\circ} \mathrm{C}$ in $\mathrm{IVM}_{2}$ medium supplemented with CCD $(1 \mu \mathrm{g} / \mathrm{ml})$ for $15 \mathrm{~min}$ prior to injection. For microinjection, oocytes were transferred to $5 \mu \mathrm{l}$ microdroplets of TL-Hepes medium plus $0.3 \%$ BSA under mineral oil. The temperature of the microdroplet was maintained at $39^{\circ} \mathrm{C}$ by means of a heated stage under the injection dish. The mitochondrial suspension was aspirated into the injection pipette until it reached a predetermined volume between 3 and $5 \mathrm{pl}$. Injection was at $3 \mathrm{o}^{\prime}$ clock in relation to the polar body at $6 \mathrm{o}^{\prime}$ clock directly into $\mathrm{BCB}^{-}$oocytes (Nikon T200 Microinjection system, Kingston upon Thames, Surrey, UK). Another group of $\mathrm{BCB}^{-}$oocytes was used for sham injection. The oocyte was penetrated with an injection pipette containing only some media. Immediately after injection, $\mathrm{BCB}^{-}$oocytes were transferred to $\mathrm{IVM}_{2}$ medium and cultured for another $24 \mathrm{~h}$ at $39^{\circ} \mathrm{C}$ in $5 \% \mathrm{CO}_{2}$ in air. After $24 \mathrm{~h}$ of culture, $\mathrm{BCB}^{+}$oocytes, $\mathrm{BCB}^{-}$ oocytes, mitochondrial supplemented $\mathrm{BCB}^{-}$oocytes and sham-injected $\mathrm{BCB}^{-}$oocytes from each ovary were inseminated either by IVF, as described previously, or by intracytoplasmic sperm injection (ICSI). Putative zygotes, subjected to either IVF or ICSI, were cultured in IVP medium and checked for cleavage after $48 \mathrm{~h}$. The fertilisation rates of $\mathrm{BCB}^{+}, \mathrm{BCB}^{-}$, supplemented $\mathrm{BCB}^{-}$and shaminjected oocytes were analysed by one-way ANOVA and Tukey's pairwise comparisons.

In a separate experiment, we again isolated pure populations of mitochondria and assessed the number of mtDNA genomes that would have been injected into the cytoplasms of $\mathrm{BCB}^{-}$oocytes.

\section{ICSI}

Following $48 \mathrm{~h}$ of in vitro maturation, oocytes were washed three times in TL-Hepes medium and were denuded of cumulus cells. The sperm suspension was added to a $10 \%$ polyvinyl pyrrolidone (PVP) solution and individual sperm were immobilised by squeezing the tail between the bottom of the dish and the injection pipette. Microinjection was performed in IVF media under mineral oil, as described above.

\section{Quality control of the mitochondrial preparation}

The enrichment of the mitochondrial preparation was assessed by visualising the mitochondria after staining the oocytes with $0.5 \mu \mathrm{g} / \mathrm{ml}$ Mito Tracker Green (Molecular Probes, Paisley, Strathclyde, UK) for $30 \mathrm{~min}$. Absence of contamination was confirmed by PCR. $\beta$-Actin gene specific primers were used to identify the presence of any nuclear debris that may be contaminating the mitochondrial preparation. Cyclin B mRNA specific primers were used to identify any contaminating gene transcripts. mtDNA D-loop primers were used to confirm the presence of mtDNA in the mitochondrial preparation. Primer details are displayed in Table 2. RNA extraction was performed using the RNAqueous-4-PCR kit (Ambion Europe Ltd, Huntingdon, Cambs, UK) according to the manufacturer's protocol. Reverse transcription was performed using the Reverse Transcription System (Promega, Southampton, Hants, UK) according to the manufacturer's protocol. PCR using $2 \mathrm{U}$ BioTaq polymerase was performed in $50 \mu \mathrm{l}$ volumes in $1 \times$ PCR buffer and $1.5 \mathrm{mM}$ $\mathrm{MgCl}_{2}$. The primer and nucleotide concentrations were $0.5 \mu \mathrm{M}$ and $200 \mu \mathrm{M}$ dNTP mix respectively. PCR reaction conditions were initial denaturation at $94^{\circ} \mathrm{C}$ for $5 \mathrm{~min}$ then 35 cycles of denaturation at $94^{\circ} \mathrm{C}$ for $1 \mathrm{~min}$, annealing at the appropriate temperature for $1 \mathrm{~min}$ (see Table 2) and extension at $72{ }^{\circ} \mathrm{C}$ for $3 \mathrm{~min}$. PCR products were resolved on $2 \%$ agarose gels. DNA preparations extracted from the oocytes, follicular fluid and sperm were used as positive controls. RNA extracted from follicular fluid was used as a positive control for cyclin B analysis.

\section{mtDNA fingerprinting analysis}

PCR amplifications of $660 \mathrm{bp}$ of the porcine D-loop region (Accession No. AF034253; nt12 - 640) were performed in $50-\mu \mathrm{l}$ reactions. Each reaction contained $200 \mathrm{ng}$ total DNA, $1 \times$ PCR buffer (BioLine), $1.5 \mathrm{mM} \mathrm{MgCl}$ (BioLine), $200 \mu \mathrm{M}$ dNTPs (BioLine), $0.5 \mu \mathrm{M}$ of each primer and $2.5 \mathrm{U}$ BioTaq DNA polymerase (BioLine). D-loop forward and reverse primers are listed in Table 2. Reaction conditions were $95^{\circ} \mathrm{C}$ for $5 \mathrm{~min}$ followed by 35 cycles of $94^{\circ} \mathrm{C}$ for $45 \mathrm{~s}, 55^{\circ} \mathrm{C}$ for $30 \mathrm{~s}$ and $72^{\circ} \mathrm{C}$ for $45 \mathrm{~s}$, and then $72^{\circ} \mathrm{C}$ for 3 min using an MJ Research PTC-200 DNA engine (GRI, Braintree, Essex, UK). PCR products were resolved on $2 \%$ agarose gels (Gibco BRL, UK) at $100 \mathrm{~V}$ for $1 \mathrm{~h}$ and product size confirmed against a $100 \mathrm{bp}$ DNA ladder (Gibco BRL). The PCR products were excised from the agarose gels and purified for DNA sequencing using the QIAquick Gel Extraction Kit (Qiagen, London, UK), as described in the manufacturer's protocol. The purified mtDNA was then sequenced using the automated direct sequencing protocol (Hopgood et al. 1991). 


\section{Results}

In order to determine the relationship between mitochondrial content, oocyte volume, oocyte growth, oocyte development and fertilisation outcome, we stained a cohort of oocytes with BCB. In each instance, we calculated their relative volumes and assessed their mitochondrial DNA copy number. There was a significant difference in oocyte volume between those oocytes staining positively for $\mathrm{BCB}$ $\left(\mathrm{BCB}^{+}\right)$and those that reduced the dye $\left(\mathrm{BCB}^{-} ; P<0.001\right.$; see Table 3). BCB selection was also reflected in fertilisation rates between the two groups, where $46.6 \%$ of $\mathrm{BCB}^{+}$ inseminated oocytes cleaved compared with $22.7 \%$ for the $\mathrm{BCB}^{-}$set $(P<0.001$; see Table 3$)$.

In order to determine whether mtDNA content could influence fertilisation outcome, we analysed the number of mtDNA copies per oocyte between fertilised and unfertilised oocytes and between $\mathrm{BCB}^{+}$and $\mathrm{BCB}^{-}$oocytes (see Table 3). In the $\mathrm{BCB}^{+}$oocyte group, the mean mtDNA copy number for fertilised oocytes was $404550 \pm 173888$ (mean \pm S.D.) copies $(n=20)$ compared with $49014 \pm 30416$ for oocytes that failed to fertilise $(n=21)$, representing a significant difference of $P<0.001$. For those $\mathrm{BCB}^{-}$fertilised oocytes, mean mtDNA copy number was $209737 \pm 101042 \quad(n=19)$ whilst for unfertilised oocytes mean mtDNA copy number was $25686 \pm 18930(n=20 ; P<0.001)$. Furthermore, there was a significant difference for mtDNA copy number between those oocytes predicted to fertilise and those predicted to fail, as assessed by BCB staining (Table 3). In addition, there was a significant difference in mtDNA copy number and volume between fertilised $\mathrm{BCB}^{+}$and unfertilised $\mathrm{BCB}^{+}$oocytes $(P<0.05)$ and between fertilised $\mathrm{BCB}^{-}$and unfertilised $\mathrm{BCB}^{-}$oocytes $(P<0.02)$ from the same ovary (data not shown).

The distribution of mitochondria among blastomeres was examined by determining mtDNA copy number in each disassociated blastomere. We analysed 10 fertilised control embryos ranging from the 2-cell to the 5-cell stage. In three of the 4-cell embryos, cleavage was not complete and therefore two blastomeres could not be separated. Combined measurements were taken and divided by 2 , resulting in the most even distribution possible being presented (see Table 4). Despite this, there is considerable asymmetrical mitochondrial distribution amongst blastomeres from the same embryo, and amongst different embryos (Table 4).

To determine whether mitochondrial content has a direct effect on oocyte development, we supplemented $\mathrm{BCB}^{-}$oocytes with purified populations of mitochondria containing $139200 \pm 34800$ copies of mtDNA. We compared their fertilisation rates after both IVF and ICSI treatment with $\mathrm{BCB}^{+}$oocytes, $\mathrm{BCB}^{-}$oocytes, and shaminjected $\mathrm{BCB}^{-}$oocytes. After both IVF and ICSI, $\mathrm{BCB}^{+}$ and $\mathrm{BCB}^{-}$oocytes with mitochondrial supplementation had significantly higher fertilisation rates $(P<0.002)$ than unsupplemented $\mathrm{BCB}^{-}$oocytes and $\mathrm{BCB}^{-}$sham-injected
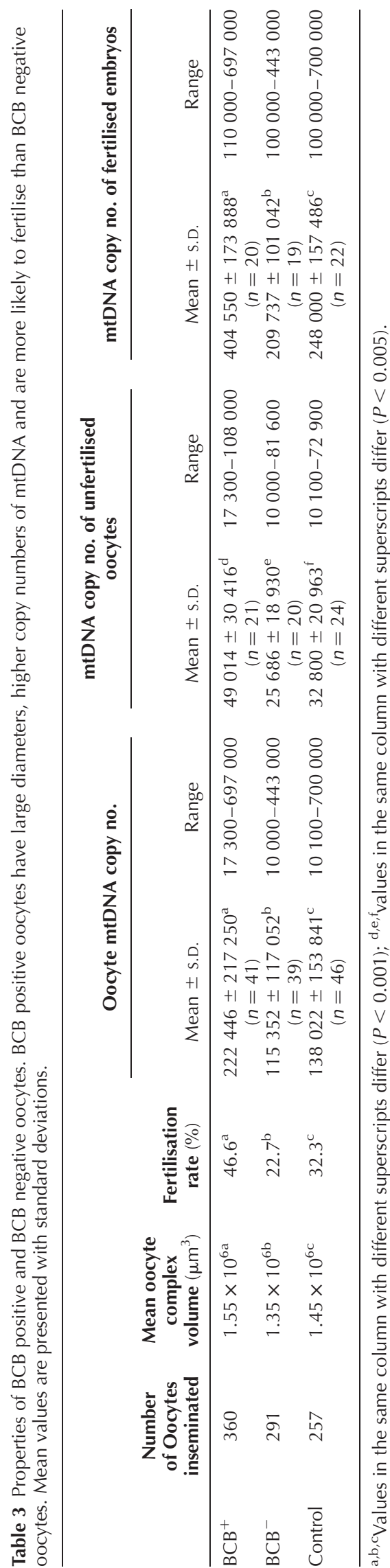

Reproduction (2006) 131 233-245

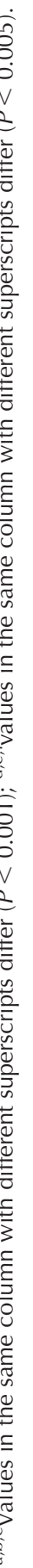

www.reproduction-online.org 
Table 4 Variation in mtDNA copy number within individual blastomeres from the same embryo, which can be more than an order of magnitude.

\begin{tabular}{|c|c|c|c|c|c|c|c|c|c|c|}
\hline & \multicolumn{10}{|c|}{ Number of blastomeres within embryo } \\
\hline & 2 & 2 & 2 & 2 & 3 & 3 & 4 & 4 & 4 & 5 \\
\hline mtDNA copy number in blastomere & $\begin{array}{r}34500 \\
117000\end{array}$ & $\begin{array}{r}31400 \\
297000\end{array}$ & $\begin{array}{l}12000 \\
88300\end{array}$ & $\begin{array}{r}97000 \\
192000\end{array}$ & $\begin{array}{l}71000 \\
37200 \\
52000\end{array}$ & $\begin{array}{l}390000 \\
100000 \\
210000\end{array}$ & $\begin{array}{ll}21 & 900 \\
21 & 900 \\
42 & 500 * \\
42 & 500 *\end{array}$ & $\begin{array}{l}153000 \\
171000 \\
145500^{*} \\
145500^{*}\end{array}$ & $\begin{array}{r}28000 \\
48300 \\
162000 * \\
162000 *\end{array}$ & $\begin{array}{r}244000 \\
106000 \\
97400 \\
16700 \\
15000\end{array}$ \\
\hline Total mtDNA copy number for embryo & 151500 & 611000 & 100300 & 289000 & 160200 & 700000 & 128800 & 615000 & 400300 & 479100 \\
\hline
\end{tabular}

* Some blastomeres had not fully divided and therefore could not be separated by pronase treatment. Values presented assume equal division of mtDNA and demonstrate minimum variation.

oocytes (see Table 5). Furthermore, the post-injection ova survival rate after both IVF and ICSI was significantly higher $(P<0.001)$ for mitochondrial-injected $\mathrm{BCB}^{-}$ oocytes (IVF $=77.8 \%$, ICSI $=78.7 \%$ ) than unsupplemented $\mathrm{BCB}^{-}$oocytes (IVF $\left.=70.5 \%, \quad \mathrm{ICSI}=69.4 \%\right)$ and sham-injected oocytes (IVF $=67.9 \%$, ICSI $=68 \%$ ). There was no significant difference $(P>0.05)$ in the percentages of oocyte fertilisation after both fertilisation techniques $\left(\mathrm{BCB}^{+}:\right.$IVF $=37.5 \%, \mathrm{ICSI}=40.4 \% ; \mathrm{BCB}^{-}$supplemented with mitochondria: IVF $=31.0 \%, \quad I C S I=34 \% ; \quad \mathrm{BCB}^{-}$: $\mathrm{IVF}=17.6 \%, \mathrm{ICSI}=19.8 \%$ ).

The donor mitochondria, derived from maternally related $\mathrm{BCB}^{+}$oocyte cytoplasts, were purified on Percoll density gradients and verified for the presence of contaminants and purity by fluorescence microscopy (data not shown) and through PCR. Figure 1A shows the presence of some nuclear debris contamination, in the form of $\beta$-actin, in the mitochondrial fraction prepared without the Percoll density gradient (lane 8), although very faint compared with the positive controls (lanes 11-13). However, it is absent in the Percoll density gradient mitochondrial preparation (lane 9). Similar results were obtained from analysis of cyclin B mRNA transcripts (Fig. 1B), which would be expected to persist in the oocyte cytoplasm (Hue et al. 1997). Cyclin B transcripts were present in the RNA extracted from follicular fluid, a positive control (lane 5). No cyclin B transcripts were present in either mitochondrial preparation, i.e. the Percoll density gradient (lane 6)

Table 5 Fertilisation rates after IVF or ICSI on oocytes with (supplemented) and without (sham injection) mitochondrial supplementation.

\begin{tabular}{lcc}
\hline Treatment & $\begin{array}{c}\text { IVF fertilisation rate } \\
(\boldsymbol{\%})\end{array}$ & $\begin{array}{c}\text { ICSI fertilisation rate } \\
(\%)\end{array}$ \\
\hline $\mathrm{BCB}^{+}$ & $37.5^{\mathrm{a}}$ & $40.4^{\mathrm{c}}$ \\
$\mathrm{BCB}^{-}$ & $17.6^{\mathrm{b}}$ & $19.8^{\mathrm{d}}$ \\
$\mathrm{BCB}^{-}$supplemented & $31.0^{\mathrm{a}}$ & $34.0^{\mathrm{C}}$ \\
$\mathrm{BCB}^{-}$sham injected & $17.0^{\mathrm{b}}$ & $10.0^{\mathrm{d}}$ \\
\hline
\end{tabular}

${ }^{a, b}$ Values in the same column with different superscripts differ $(P<0.002)$; ${ }^{\mathrm{c}, \mathrm{d}}$ values in the same column with different superscripts differ $(P<0.001)$. and the non-Percoll density gradient (lane 7). However, some contaminating cyclin B DNA was observed in the non-Percoll density gradient mitochondrial preparation (lane 7) and in the intermediate supernatant from the purification process (lane 8).

Interestingly, the oocytes used in these studies were obtained from a commercial dam line of pure white pigs. Our mtDNA sequence analysis of 37 pigs representative of several breeding groups demonstrates that all the pigs arose from one original mtDNA ancestor belonging to haplotype A, as defined by Alves et al. (2003). This indicates that all the reconstructed oocytes were homoplasmic. Furthermore, the mean litter size for these pigs is $11.33 \pm 2.96$, demonstrating the variable fertilisation efficiency of the oocytes.

\section{Discussion}

It is well established that mammalian immature oocytes are heterogeneous in quality and developmental competence (Shea et al. 1975). There is considerable morphological variability among oocytes capable of normal development, and assessment of morphology has led to some improvements in the identification of oocytes that would develop in vitro (De Loose et al. 1992). Although morphology can indicate maturity and fertilisation potential (Madison et al. 1992), even after careful selection on the basis of visual appearance, $10-20 \%$ of harvested immature oocytes from slaughterhouse pig ovaries degenerate during sperm co-incubation (Matas et al. 1996). This suggests that other approaches warrant investigation.

Increases in the production and storage of energy substrates are vital to oocyte growth and therefore oocyte maturation and early embryonic development. These processes require NADPH production via the pentose phosphate pathway (Cetica et al. 2002). The pentose phosphate pathway has also been demonstrated to be involved in the meiotic induction of mouse oocytes (Downs et al. 1998). Completion of the pentose phosphate pathway activities during oocyte maturation is therefore likely to significantly increase fertilisation and developmental success, which we have demonstrated through 


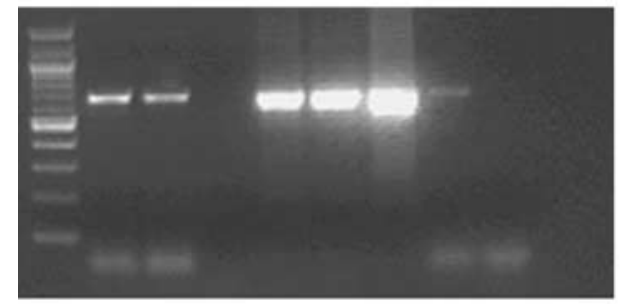

$\begin{array}{llllllllll}M & 1 & 2 & 3 & 4 & 5 & 6 & 7 & N\end{array}$

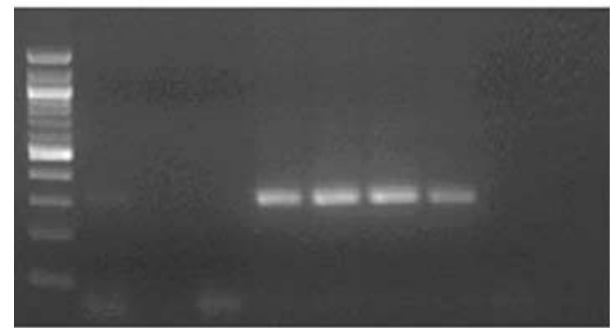

M $8 \quad 9 \quad 1011121314 \quad N$

(A)
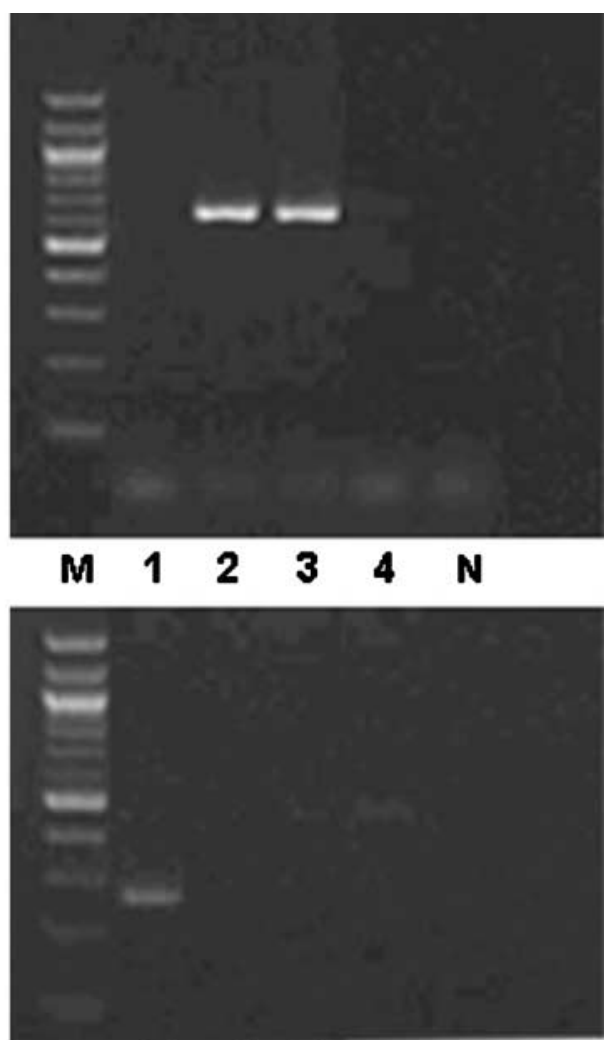

$\begin{array}{llllll}M & 5 & 6 & 7 & 8 & N\end{array}$

(B)

Figure 1 Confirmation of the purity of mitochondrial preparation. (A) $\beta$-Actin analysis to determine nuclear DNA contamination. Lanes 1 to 7 are mtDNA PCR product; lanes 8 to 14 are $\beta$-actin product. The mitochondria prepared without the Percoll density gradient (lanes 1 and 8 ) have some $\beta$-actin contamination; the Percoll density gradient mitochondrial preparation (lanes 2 and 9) contains no $\beta$-actin contamination; positive controls are supernatant (lanes 3 and 10), sperm (lanes 4 and 11), oocytes (lanes 5 and 12), and follicular fluid (lanes 6 and 13). Some mitochondria were still present in the nuclear pellet (lanes 7 and 14). M, 100 bp ladder (Gibco BRL); N, negative PCR control. (B) Cyclin B mRNA analysis to determine transcript contamination. Lanes 1 to 4 are mtDNA PCR product; lanes 5 to 8 are cyclin B transcripts. Lanes 2 to 4 demonstrate the presence of mtDNA in mitochondrial preparations purified using the Percoll density gradient (lane 2), without the Percoll density gradient (lane 3 ) and in an intermediate supernatant from the purification process (lane 4). No mtDNA D-loop (the only non-encoded region of the mtDNA genome) product was present in RNA extracted from follicular fluid (lane 1). Cyclin B transcripts are only present in the follicular fluid RNA extract (lane 5). However, there are faint traces of cyclin B DNA in the non-Percoll density gradient mitochondrial preparation (lane 7) and the supernatant (lane 8). No cyclin B transcripts or DNA are present in the Percoll density gradient mitochondrial preparation used for supplementation (lane 6). M, 100 bp ladder (Gibco BRL); N, negative PCR control.

$\mathrm{BCB}$ staining of porcine oocytes. In this instance, $\mathrm{BCB}^{+}$ oocytes that had completed the growth phase of maturation and no longer contained G6PD, the rate-limiting enzyme of the pentose phosphate pathway, were more likely to fertilise and to survive to the later stages of preimplantation development compared with the $\mathrm{BCB}^{-}$oocytes still containing G6PD.

We have further analysed the role of mtDNA in successful fertilisation and development of pig oocytes. In this respect, $\mathrm{BCB}^{+}$oocytes have a larger cytoplasmic volume $\left(1.55 \times 10^{6} \mu \mathrm{m}^{3}\right.$ vs $\left.1.35 \times 10^{6} \mu \mathrm{m}^{3}\right)$, are more likely to fertilise and contain far higher numbers of mtDNA than $\mathrm{BCB}^{-}$oocytes. This is in accordance with previous reports where individually both diameter (Raghu et al. 2002), an essential component of volume, and mtDNA copy number (Reynier et al. 2001), have been linked to fertilisation outcome in the buffalo and human respectively. Additionally, increased mitochondrial number correlates to cytoplasmic volume in cattle (Smith \& Alcivar 1993). However, our porcine oocyte data would suggest that a correlation exists between increased cytoplasmic volume and increased mtDNA content, and that there appears to be a distinct relationship between mtDNA content and fertilisation outcome.

The likely outcome for those oocytes with low mtDNA copy numbers $(<100000)$, based on the lowest copies of mtDNA associated with the control group, and consequently those that fail to fertilise is that in the advanced blastocyst they would be compromised through severe mtDNA depletion. Throughout early embryogenesis, there is a continual dilution of the mtDNA genome due to the ever-increasing numbers of blastomeres and the lack of 
mtDNA replenishment. In the mouse, mtDNA replication does not appear to ensue until after implantation (Larsson et al. 1998), or at least until the post-blastocyst stage (Piko \& Taylor 1987). This is exemplified in both undifferentiated human embryonic stem cells (Sathananthan et al. 2002, St John et al. 2005) and primordial oocytes (Jansen \& De Boer 1998) where low levels of mitochondria have been observed. Mitochondrial content would then exponentially increase during the differentiation processes leading to final cellular fate or, in the case of oocytes, up to MII (Smith \& Alcivar 1993, Jansen \& De Boer 1998). This highly regulated process ensures that appropriate numbers of mitochondria would be available to support cellular metabolism in fully functional cells.

The absence of mtDNA replication during the cleavage stages of embryonic development (Piko \& Taylor 1987) is thought to function as a genetic 'bottleneck', thereby restricting segregation to the primordial germ cells, and consequently inheritance to the next generation, in order to maintain homoplasmy (Marchington et al. 1997). A homoplasmic population of mtDNA would be preferable to produce an efficient ETC since single point mutations and large-scale deletions can lead to the onset of mtDNAtype disease (Wallace 1999). The onset of mtDNA disease is determined by the ratio of mutant to wild-type present (heteroplasmy; Chinnery et al. 2001). In those oocytes carrying mtDNA-type mutations or deletions (Blok et al. 1997), their survival during early embryo development would be dependent on the degree of mutant molecule present. As long as these oocytes contained significant copies of the wild-type mtDNA genome to ensure successful fertilisation, it is likely that they would progress to the onset of mtDNA replication. It is then during gastrulation that the anticipated segregation of mtDNA mutations would take place, most likely affecting high-ATP requiring tissues such as neuronal and muscle tissue (Moyes et al. 1998).

The precise onset of mtDNA transcription and replication relies on nuclear-encoded transcription factors being translocated to the mitochondria (Clayton 1998). One particular transcription factor, mitochondrial transcription factor A (TFAM), has been implicated in mtDNA copy number regulation and is associated with mtDNAdepletion disease (Larsson et al. 1994, Poulton et al. 1994, Spelbrink et al. 1998, Tessa et al. 2000). TFAM is first expressed post-gastrulation in murine embryos (Larsson et al. 1998) as is the mtDNA-specific polymerase $\gamma$ (PolG; Hance et al. 2005). Failure to initiate mtDNA replication shortly after implantation would probably result in embryos failing to survive, as is the case in homozygous knockout mice for TFAM (Larsson et al. 1998) and the PolG (Hance et al. 2005). Consequently, it would appear that the fertilised oocyte must have an appropriate amount of mtDNA present in order for TFAM and PolG to initiate mtDNA replication. Failure to do so would result in the onset of mtDNA-depletion type syndromes, as evidenced in heterozygous TFAM knockouts which exhibit severe cardiomyopathy ( $\mathrm{Li}$ et al. 2000). Interestingly, a recent report indicates that an early window of mtDNA turnover takes place at the one- to two-cell stage in murine embryos (McConnell \& Petrie 2004). Although no expansion of mtDNA copy number takes place at this stage, acquired levels could be maintained, thus potentially safeguarding those oocytes being borderline for fertilisation success and subsequent embryonic development.

Our analysis of developmentally competent and incompetent oocytes suggests a mitochondrial threshold relative to fertilisation outcome and subsequent embryonic development. This is implied by our supplementation of developmentally incompetent oocytes, as indicated by their $\mathrm{BCB}^{-}$status, with donor mtDNA. In this instance, these oocytes were rescued from probable fertilisation and developmental failure by purified and concentrated mitochondrial preparations containing $139200 \pm 34800$ copies of mtDNA. This would enhance the mean mtDNA copy number for these $\mathrm{BCB}^{-}$oocytes from 115352 to 254552 copies, which lies within the range for $\mathrm{BCB}^{+}$ oocytes. Consequently, it would appear that mitochondria and/or mtDNA alone could influence fertilisation outcome. This clearly discriminates between the other factors, such as maternal RNAs that were most likely transferred during CT (Cohen et al. 1997), and have been suggested to be a putative trigger for subsequent development. In addition, the similarity in fertilisation outcomes between ICSI and IVF post-mitochondrial supplementation would indicate an oocyte- rather than a sperm-related factor affecting developmental outcome. This approach also eliminates the bias that might result from polyspermic fertilisation in the IVF group.

Interestingly, our data not only indicate considerable variation in oocyte mtDNA copy number (10000 to $700000)$ but we also observe this trend amongst intra-embryo blastomeres (see Table 4). This is in agreement with a previous report in the human (Lin et al. 2004) suggesting that this might not be a species-specific event. This unequal distribution may explain why some blastomeres survive and divide, i.e. those having sufficient mtDNA copy numbers, while others fragment due to insufficient mtDNA copy number, resulting in diminished ATP generation (Van Blerkom et al. 2000) or mtDNA-driven atresia (Krakauer \& Mira 1999). Indeed, blastomere fragmentation is associated with blastocysts presenting with lower cell numbers, a factor well known to be associated with reduced developmental success (Park et al. 2005).

The ratio of mtDNA copies to the mitochondrion tends to be cell specific (see St John et al. 2004a,b for discussion). In the mouse (Piko \& Taylor 1987) and frog (Marinos \& Billett 1981), the oocyte mitochondrion contains only one copy of the mitochondrial genome, as is also hypothesised for human oocytes (Jansen \& De Boer 1998). Other cell types, such as neurones and muscle cells possess 
between 8 and $10 \mathrm{mtDNA}$ copies per mitochondrion (reviewed in Moyes et al. 1998). Consequently, the mtDNA copy numbers we observe in porcine oocytes could also reflect their respective mitochondrial number. Should the pig possess more than one mtDNA copy per oocyte mitochondrion, then the number of mtDNA copies present would still be proportional to the number of mitochondria also present.

Cellular ATP is most effectively generated through OXPHOS and therefore relies on gene products for the ETC being derived from both the mitochondrial and nuclear genomes. The importance of ATP levels in developing oocytes has been demonstrated in bovine oocytes where higher quality oocytes, assessed by morphology, contained significantly higher ATP levels and produced significantly higher blastocyst rates after fertilisation (Stojkovic et al. 2001). In the pig during the maturation process, oxidative capacity is highest in those oocytes exhibiting granulated heterogeneous and clustered heterogeneous distributions of mitochondria which would indicate their readiness for fertilisation (Torner et al. 2004). It is, however, evident that inhibition of OXPHOS function at the compaction stage in porcine embryos can improve embryo viability (Machaty et al. 2001). Indeed, similar outcomes have been demonstrated in other mammalian species where the switch from OXPHOS to glycolysis takes place during cavitation (see Van Blerkom et al. 2000 for discussion). However, one report in the mouse indicates that total oxygen consumed by OXPHOS is higher in blastocysts than in other earlier staged embryos (Trimarchi et al. 2000). For the porcine system, this developmental switch to glycolysis would support the view that the non-replenishment of mitochondrial proteins of the ETC was reaching a critical phase and that a compensatory mechanism would be required to maintain embryo survival. A similar situation exists in somatic cells undergoing depletion of their mtDNA genomes. They cannot replicate mtDNA, nor can they survive if they are not supported by metabolic substrates that drive glycolysis (King \& Attardi 1989). This is further evident in those blastomeres with very low mtDNA copy number where survival based on OXPHOS alone would be disadvantageous. This switch from OXPHOS to glycolysis would thus rescue them from metabolic crisis and support their persistence to participate at blastocyst.

The high numbers of mitochondria and mtDNA required to support fertilisation may also facilitate the distribution of ATP throughout the cell. Mitochondria form networks throughout the cell, with the distribution pattern being specific for different stages of the cell cycle (Margineantu et al. 2002). Mature and immature oocytes also have distinct patterns of mitochondrial distribution in cattle (Stojkovic et al. 2001), mice (Nishi et al. 2003), and the pig (Torner et al. 2004). Consequently, those oocytes with low mtDNA copy number may be unable to form the networks required for developmental competence, as observed in some porcine parthenogenetically activated oocytes (Brevini et al. 2005). Furthermore, mitochondria have been shown to act as calcium sinks in sea urchin oocytes (Eisen \& Reynolds 1985). Through their uptake of $\mathrm{Ca}^{2+}$, mitochondria are able to maintain the $\mathrm{Ca}^{2+}$ wave pacemaker that is necessary for completion of meiosis (Dumollard et al. 2003). Failure to maintain the $\mathrm{Ca}^{2+}$ wave pacemaker, for which mitochondria are also well-known mediators (Zamzami et al. 1996), results in apoptotic cell death of the oocyte (Liu et al. 2001).

Our supplementation protocol has enabled us to generate homoplasmic viable oocytes which would thus maintain the genetic integrity of the embryo and any subsequently derived offspring. This could overcome one of the major failings related to human clinical cytoplasmic transfer (St John \& Barratt 1997, St John 2002a, St John et al. 2004a,b), where supplementation with donor cytoplasm has been proposed as a means of enhancing embryonic development for those women with repeated embryo development failure. Current cytoplasmic transfer practises can result in the transmission of donor and recipient oocyte mtDNA to the offspring (Brenner et al. 2000). Similar heteroplasmic patterns of mtDNA transmission have been observed in nuclear transfer generated embryos and offspring, discussed in St John et al. (2004a,b). Furthermore, the transfer of the same mtDNA source would reduce possible compromised OXPHOS function that could arise through mixing of mtDNA genotypes (McKenzie \& Trounce 2000, and discussed extensively in St John \& Barratt 1997 and St John 2002a). As a strong point of caution, our data do not, however, suggest that any of the resulting disorders associated with cytoplasmic transfer (Barritt et al. 2001b) might be overcome.

It is becoming increasingly apparent that mitochondria could be vital to oocyte maturation and subsequent embryonic development. They also provide a vehicle for the transmission of mtDNA to subsequent generations. Whilst OXPHOS is vital for early porcine embryonic development, the switch to glycolysis at compaction in the porcine system allows this critical mass of mitochondria to be maintained and its contents transmitted to subsequent generations. Mitochondrial assessment prior to any oocyte reconstruction protocol would allow fertilisable oocytes to be selected. Consequently, this might enhance success rates for those technologies which currently have low efficiencies, such as nuclear transfer (Wilmut et al. 1997), as these technologies may currently be hampered by the removal of some mitochondria during the enucleation procedure.

\section{Acknowledgements}

This work was partly funded by a research grant from Birmingham Womens Health Care Trust. The authors declare that there is no conflict of interest that would prejudice the impartiality of this scientific work. 


\section{References}

Abeydeera LR \& Day BN 1997 Fertilisation and subsequent development in vitro of pig oocytes inseminated in modified Tris-buffered medium with frozen thawed ejaculated spermatozoa. Biology of Reproduction 57 729-734.

Alves E, Óvilo C, Rodríguez MC \& Silió L 2003 Mitochondrial DNA sequence variation and phylogenetic relationships among Iberian pigs and other domestic and wild pig populations. Animal Genetics 34 319-324.

Anderson S, Bankier AT, Barrell BG, de Bruijn MHL, Coulson AR, Drouin J, Eperon IC, Nierlich DP, Roe BA, Sanger F, Schreier PH, Smith AJH, Staden R \& Young IG 1981 Sequence and organization of the human mitochondrial genome. Nature $\mathbf{2 9 0}$ 457-465.

Barritt JA, Brenner CA, Malter HE \& Cohen J 2001 a Mitochondria in human offspring derived from ooplasmic transplantation. Human Reproduction 16 513-516.

Barritt J, Brenner C, Malter H \& Cohen J 2001b Rebuttal: interooplasmic transfers in humans. Reproductive Biomedicine Online 3 47-48.

Barritt JA, Kokot M, Cohen J, Steuerwald N \& Brenner CA 2002 Quantification of human ooplasmic mitochondria. Reproductive Biomedicine Online 4 243-247.

Blok RB, Gook DA, Thorburn DR \& Dahl HH 1997 Skewed segregation of the mtDNA nt $8993(T \rightarrow G)$ mutation in human oocytes. American Journal of Human Genetics $\mathbf{6 0}$ 1495-1501.

Brenner CA, Barritt JA, Willadsen S \& Cohen J 2000 Mitochondrial DNA heteroplasmy after human ooplasmic transplantation. Fertility and Sterility $\mathbf{7 4}$ 573-578.

Brevini TA, Vassena R, Francisci C \& Gandolfi F 2005 Role of adenosine triphosphate, active mitochondria, and microtubules in the acquisition of developmental competence of parthenogenetically activated pig oocytes. Biology of Reproduction 72 1218-1223.

Cetica P, Pintos L, Dalvit G \& Beconi M 2002 Activity of key enzymes involved in glucose and triglyceride catabolism during bovine oocyte maturation in vitro. Reproduction 124 675-681.

Chinnery PF, Andrews RM, Turnbull DM \& Howell NN 2001 Leber hereditary optic neuropathy: does heteroplasmy influence the inheritance and expression of the G11778A mitochondrial DNA mutation? American Journal of Medical Genetics 98 235-243.

Clayton DA 1998 Nuclear-mitochondrial intergenomic communication. Biofactors $7203-205$.

Cohen J, Scott R \& Schimmel T 1997 Birth of infant after transfer of anuclear donor oocyte cytoplasm into recipient eggs. Lancet $\mathbf{3 5 0}$ $186-187$.

Cohen J, Scott R, Alikani M, Schimmel T, Munne S, Levron J, Wu L, Brenner C, Warner C \& Willadsen S 1998 Ooplasmic transfer in mature human oocytes. Molecular Human Reproduction $\mathbf{4}$ 269-280.

Cran DG 1985 Qualitative and quantitative structural changes during pig oocyte maturation. Journal of Reproduction and Fertility $\mathbf{7 4}$ 237-245.

De Loose F, Van Maurik P, Van Beneden T \& Kruip TA 1992 Structural aspect of bovine oocyte maturation in vitro. Molecular Reproduction and Development 31 208-214.

Downs SM, Humpherson PG \& Leese HJ 1998 Meiotic induction in cumulus cell-enclosed mouse oocytes: involvement of the pentose phosphate pathway. Biology of Reproduction $\mathbf{5 8}$ 1084-1094.

Dumollard R, Hammar K, Porterfield M, Smith PJ, Cibert C, Rouviere C \& Sardet C 2003 Mitochondrial respiration and $\mathrm{Ca}^{2+}$ waves are linked during fertilisation and meiosis completion. Development $130683-692$.
Eisen A \& Reynolds GT 1985 Source and sinks for the calcium released during fertilization of single sea urchin eggs. Journal of Cell Biology $1001522-1527$.

Findlay I, Atkinson G, Chambers M, Quirke P, Campbell J \& Rutherford A 1996 Rapid genetic diagnosis at 7-9 weeks gestation: diagnosis of sex, single gene defects and DNA fingerprint from coelomic samples. Human Reproduction 11 2548-2553.

Fong C, Bongso A, Sathananthan H, Ho J \& Ng S 2001 Ultrastructural observation of enzymatically treated human blastocysts: zona-free blastocyst transfer and rescue of blastocysts with hatching difficulties. Human Reproduction 16 540-546.

Hance N, Ekstrand MI \& Trifunovic A 2005 Mitochondrial DNA polymerase gamma is essential for mammalian embryogenesis. Human Molecular Genetics 14 1775-1783.

Hopgood R, Sullivan KM \& Gill P 1991 Strategies for automated sequencing of human mitochondrial DNA directly from PCR products. Biotechniques 13 82-92.

Hue I, Dedieu T, Huneau D, Ruffini S, Gall L \& Crozet N 1997 Cyclin B1 expression in meiotically competent and incompetent goat oocytes. Molecular Reproduction and Development $47222-228$.

Jansen RP \& De Boer KC 1998 The bottleneck: mitochondrial imperatives in oogenesis and ovarian follicular fate. Molecular and Cellular Endocrinology 145 81-88.

King MP \& Attardi G 1989 Human cells lacking mtDNA: repopulation with exogenous mitochondria by complementation. Science 246 500-503.

Koo D, Kang Y, Choi Y, Park JS, Han S, Park I, Kim S, Lee K, Son D, Chang W \& Han Y 2000 In vitro development of reconstructed porcine oocytes after somatic cell nuclear transfer. Biology of Reproduction 63 986-992.

Krakauer DC \& Mira A 1999 Mitochondria and germ-cell death. Nature 400 125-126.

Larsson NG, Oldfors A, Holme E \& Clayton DA 1994 Low levels of mitochondrial transcription factor $\mathrm{A}$ in mitochondrial DNA depletion. Biochemical and Biophysical Research Communications 200 1374-1381.

Larsson NG, Wang J, Wilhelmssohn H, Oldfers A, Rustin P, Lewandoski M, Barsh GS \& Clayton DA 1998 Mitochondrial transcription factor $\mathrm{A}$ is necessary for mitochondrial DNA maintenance and embryogenesis in mice. Nature Genetics 18 231-236.

Li H, Wang J, Wilhelmsson H, Hansson A, Thoren P, Duffy J, Rustin P \& Larsson NG 2000 Genetic modification of survival in tissuespecific knockout mice with mitochondrial cardiomyopathy. PNAS $973467-3472$.

Lin DPC, Huang CC, Wu HM, Cheng TC, Chen CI \& Lee MS 2004 Comparison of mitochondrial DNA contents in human embryos with good or poor morphology at the 8-cell stage. Fertility and Sterility 81 73-79.

Liu L, Hammar K, Smith PJS, Inoue S \& Keefe DL 2001 Mitochondrial modulation of calcium signalling at the initiation of development. Cell Calcium 30 423-433.

McConnell JM \& Petrie L 2004 Mitochondrial DNA turnover occurs during preimplantation development and can be modulated by environmental factors. Reproductive Biomedicine Online $\mathbf{9}$ 418-424.

Machaty Z, Thompson JG, Abeydeera LR, Day BN \& Prather RS 2001 Inhibitors of mitochondrial ATP production at the time of compaction improve development of in vitro produced porcine embryos. Molecular Reproduction and Development 58 39-44.

McKenzie M \& Trounce I 2000 Expression of Rattus norvegicus mtDNA in Mus musculus cells results in multiple respiratory chain defects. Journal of Biological Chemistry 275 31514-31519.

Madison V, Avery B \& Greve T 1992 Selection of immature bovine oocytes for developmental potential in vitro. Animal Reproduction Science 27 1-11.

Marchal R, Feugang JM, Perreau C, Venturi E, Terqui M \& Mermillod P 2001 Meiotic and developmental competence of prepubertal and adult swine oocytes. Theriogenology 56 17-29. 
Marchington DR, Hartshorne GM, Barlow D \& Poulton J 1997 Homopolymeric tract heteroplasmy in mtDNA from tissues and single oocytes: support for a genetic bottleneck. American Journal of Human Genetics 60 408-416.

Margineantu DH, Cox WG, Sundell L, Sherwood SW, Beecham JM \& Capaldi RA 2002 Cell cycle dependent morphology changes and associated redistribution in mitochondria of human cell lines. Mitochondrion 1 425-435.

Marinos E \& Billett FS 1981 Mitochondrial number, cytochrome oxidase and succinic dehydrogenase activity in Xenopus laevis oocytes. Journal of Embryology and Experimental Morphology 62 395-409.

Matas C, Martinez E, Vazquez JM, Roca J \& Gadea J 1996 In vitro penetration assay of boar sperm fertility: effect of various factors on the penetrability of immature pig oocytes. Theriogenology 46 503-513.

May-Panloup P, Chretien MF, Jacques C, Vasseur C, Jean M, Malthiery Y \& Reynier P 2005 Low sperm mitochondrial DNA content in ovarian insufficiency. Human Reproduction 20 593-597.

Michaels GS, Hauswirth WW \& Laipis PJ 1982 Mitochondrial DNA copy number in bovine oocytes and somatic cells. Developmental Biology 94 246-251.

Moyes CD, Battersby BJ \& Leary SC 1998 Regulation of muscle mitochondrial designs. Journal of Experimental Biology 201 299-307.

Nishi Y, Takeshita T, Sato K \& Araki T 2003 Change in mitochondrial distribution in mouse ooplasm during in vitro maturation. Journal of Nippon Medical School 70 408-415.

Park JI, Hong JY, Yong HY, Hwang WS, Lim JM \& Lee ES 2005 High oxygen tension during in vitro oocyte maturation improves in vitro development of porcine oocytes after fertilization. Animal Reproduction Science 87 133-141.

Petters RM \& Wells KD 1993 Culture of pig embryos. Journal of Reproduction and Fertility 48 (Supplement) 61-73.

Piko L \& Taylor KD 1987 Amounts of mtDNA and abundance of some mitochondrial gene transcripts in early mouse embryos. Developmental Biology 123 364-374.

Poulton J, Morten K, Freeman-Emmerson C, Potter C, Sewry C, Dubowitz V, Kidd H, Stephenson J, Whitehouse W \& Hansen FJ 1994 Deficiency of the human mitochondrial transcription factor h-mtTFA in infantile mitochondrial myopathy is associated with mtDNA depletion. Human Molecular Genetics 3 $1763-1769$.

Raghu HM, Nandi S \& Reddy SM 2002 Follicle size and oocyte diameter in relation to developmental competence of buffalo oocytes in vitro. Reproduction, Fertility and Development 14 55-61.

Reynier P, May-Panloup P, Chretien MF, Morgan CJ, Jean M, Savagner F, Barriere P \& Malthiery Y 2001 Mitochondrial DNA content affects the fertilizability of human oocytes. Molecular Human Reproduction 7 425-429.

Roca J, Martinez E, Vazquez JM \& Lucas X 1998 Selection of immature pig oocytes for homologous in vitro penetration assays with the brilliant cresyl blue test. Reproduction, Fertility and Development 10 479-485.

Rodriguez-Gonzalez E, Lopez-Bejar M, Velilla E \& Paramio MT 2002 Selection of prepubertal goat oocytes using the brilliant cresyl blue test. Theriogenology 57 1397-1409.

Sathananthan H, Pera M \& Trounson A 2002 The fine structure of human embryonic stem cells. Reproductive Biomedicine Online 4 56-61.

Shea BF, Baker RD \& Latour JP 1975 Human follicular oocytes and their maturation in vitro. Fertility and Sterility 26 1075-1082.

Smith LC \& Alcivar AA 1993 Cytoplasmic inheritance and its effects on development and performance. Journal of Reproduction and Fertility 48 (Supplement) 31-43.

Spelbrink JN, Van Galen MJ, Zwart R, Bakker HD, Rovio A, Jacobs HT \& Van den Bogert C 1998 Familial mitochondrial DNA depletion in liver: haplotype analysis of candidate genes. Human Genetics 102 327-331.

Steuerwald N, Barrit JA, Adler R, Malter H, Schimmel T, Cohen J \& Brenner CA 2000 Quantification of mtDNA in single oocytes, polar bodies and subcellular components by real-time rapid cycle fluorescence monitored PCR. Zygote 9 209-215.

St John JC 2002a The need to investigate the transmission of mitochondrial DNA following cytoplasmic transfer. Human Reproduction 17 1954-1958.

St John JC 2002b Transmission of mtDNA following assisted reproductive techniques. Theriogenology 57 109-123.

St John JC \& Barratt CLR 1997 Use of anucleate donor oocyte cytoplasm in recipient eggs. Lancet 350 961-962.

St John JC, Lloyd R \& El Shourbagy S 2004a The potential risks of abnormal transmission of mtDNA through assisted reproductive technologies. Reproductive Biomedicine Online 8 34-44.

St John JC, Lloyd R, Bowles E, Thomas E \& El Shourbagy S 2004b Mitochondrial DNA transmission and cloning outcomes. Reproduction 127 631-641.

St John JC, Ramalho-Santos J, Gray HL, Petrosko P, Rawe VY, Navara CS, Simerly CR \& Schatten GP 2005 The expression of mitochondrial DNA transcription factors during early cardiomyocyte in vitro differentiation from human embryonic stem cells. Cloning and Stem Cells 7 141-153.

Stojkovic M, Machado SA, Stojkovic P, Zakhartchenko V, Hutzler P, Goncalves PB \& Wolf E 2001 Mitochondrial distribution and adenosine triphosphate content of bovine oocytes before and after in vitro maturation: correlation with morphological criteria and developmental capacity after in vitro fertilisation and culture. Biology of Reproduction 64 904-909.

Sun QY, Wu GM, Lai L, Park KW, Cabot R, Cheong HT, Day BN, Prather RS \& Schatten H 2001 Translocation of active mitochondria during pig oocyte maturation, fertilization and early embryo development in vitro. Reproduction 122 155-163.

Tessa A, Manca ML, Mancuso M, Renna MR, Murri L, Martini B, Santorelli FM \& Siciliano G 2000 Abnormal H-TFAM in a patient harboring a single mtDNA deletion. Functional Neurology 15 $211-214$

Tian WN, Braunstien LD, Prang J, Stuhlmeir KM, Xiq C, Tian X \& Stanton RC 1998 Importance of G6PD activity for cell growth. Journal of Biological Chemistry 273 10609-10617.

Torner H, Brussow KP, Alm H, Ratky J, Pohland R, Tuchscherer A \& Kanitz W 2004 Mitochondrial aggregation patterns and activity in porcine oocytes and apoptosis in surrounding cumulus cells depends on the stage of pre-ovulatory maturation. Theriogenology 61 1675-1689.

Trimarchi JR, Liu L, Porterfield DM, Smith PJ \& Keefe DL 2000 Oxidative phosphorylation-dependent and -independent oxygen consumption by individual preimplantation mouse embryos. Biology of Reproduction 62 1866-1874.

Ursing BM \& Arnason U 1998 The complete mitochondrial DNA sequence of the pig (Sus scrofa). Journal of Molecular Evolution 47 $302-306$

Van Blerkom J, Davis P \& Lee J 1995 ATP content of human oocytes and developmental potential and outcome after in vitro fertilisation and embryo transfer. Human Reproduction 10 415-424.

Van Blerkom J, Sinclair J \& Davis P 1998 Mitochondrial transfer between oocytes: potential application of mitochondrial donation and the issue of heteroplasmy. Human Reproduction 13 2857-2868.

Van Blerkom J, Davis P \& Alexander S 2000 Differential mitochondrial distribution in human pronuclear embryo lead to disproportionate inheritance between blastomeres: relationship to microtubular organization, ATP content and competence. Human Reproduction 15 2621-2633.

Wakayama T \& Yanagimachi R 1998 Fertilisability and developmental ability of mouse oocytes with reduced amounts of cytoplasm. Zygote 6 341-346. 
Wallace DC 1999 Mitochondrial diseases in man and mouse. Science 283 1482-1488.

Wilmut I, Schnieke AE, McWhir J, Kind AJ \& Campbell KH 1997 Viable offspring derived from foetal and adult mammalian cells. Nature 385 810-813.

Zamzami N, Susin SA, Marchetti P, Hirsch T, Gomez-Monterrey I, Castedo M \& Kroemer G 1996 Mitochondrial control of nuclear apoptosis. Journal of Experimental Medicine 183 $1533-1544$.
Zernicka-Goetz M 1998 Fertile offspring derived from mammalian eggs lacking either animal or vegetal poles. Development 125 4803-4808.

Received 29 October 2004

First decision 5 January 2005

Revised manuscript received 1 July 2005

Accepted 11 October 2005 